\title{
Flavonols Protect Against UV Radiation-Induced Thymine Dimer Formation in an Artificial Skin Mimic
}

Sabia Maini, Brian M. Fahlman and Ed S. Krol

Drug Discovery and Development Research Group, College of Pharmacy and Nutrition, University of Saskatchewan, 107 Wiggins Rd, Saskatoon, SK, Canada

Received, June 29, 2015; Revised, August 18, 2015; Accepted, September 21, 2015; Published, October 13, 2015.

\begin{abstract}
Purpose: Exposure of skin to ultraviolet light has been shown to have a number of deleterious effects including photoaging, photoimmunosuppression and photoinduced DNA damage which can lead to the development of skin cancer. In this paper we present a study on the ability of three flavonols to protect EpiDerm $^{\mathrm{TM}}$, an artificial skin mimic, against UV-induced damage. Methods: EpiDerm ${ }^{\mathrm{TM}}$ samples were treated with flavonol in acetone and exposed to UVA $\left(100 \mathrm{~kJ} / \mathrm{m}^{2}\right.$ at $\left.365 \mathrm{~nm}\right)$ and UVB $\left(9000 \mathrm{~J} / \mathrm{m}^{2}\right.$ at $\left.310 \mathrm{~nm}\right)$ radiation. Secretion of matrix metalloproteinase-1 (MMP-1) and tumor necrosis factor- $\alpha$ (TNF- $\alpha$ ) were determined by ELISA, cyclobutane pyrimidine dimers were quantified using LC-APCI-MS. Results: EpiDerm TM treated topically with quercetin significantly decreased MMP-1 secretion induced by UVA $(100 \mu \mathrm{M})$ or UVB $(200 \mu \mathrm{M})$ and TNF- $\alpha$ secretion was significantly reduced at $100 \mu \mathrm{M}$ quercetin for both UVA and UVB radiation. In addition, topically applied quercetin was found to be photostable over the duration of the experiment. EpiDerm $^{\mathrm{TM}}$ samples were treated topically with quercetin, kaempferol or galangin $(52 \mu \mathrm{M})$ immediately prior to UVA or UVB exposure, and the cyclobutane thymine dimers (T-T (CPD)) were quantified using an HPLCAPCI MS/MS method. All three flavonols significantly decreased T-T (CPD) formation in UVB irradiated EpiDerm $^{\mathrm{TM}}$, however no effect could be observed for the UVA irradiation experiments as thymine dimer formation was below the limit of quantitation. Conclusions: Our results suggest that flavonols can provide protection against UV radiation-induced skin damage through both antioxidant activity and direct photoabsorption.
\end{abstract}

This article is open to POST-PUBLICATION REVIEW. Registered readers (see "For Readers") may comment by clicking on ABSTRACT on the issue's contents page.

\section{INTRODUCTION}

Ultraviolet radiation (UVR), defined as electromagnetic radiation in the range of $100 \mathrm{~nm}$ to $400 \mathrm{~nm}$, accounts for $10 \%$ of the solar radiation that reaches the earth (1). Of this radiation, the ultraviolet C (UVC) portion $(<280 \mathrm{~nm})$ and $90-99 \%$ of the ultraviolet B (UVB) $(280 \mathrm{~nm}-315 \mathrm{~nm})$ is filtered by atmospheric ozone, leaving ultraviolet A (UVA) $(315 \mathrm{~nm}-400 \mathrm{~nm})$ as the major component of ultraviolet radiation to reach the earth's surface (1).

The UVR that reaches the earth's surface has a number of effects on mammalian systems. Ultraviolet radiation is responsible for regulation of circadian rhythms and for the conversion of 7dehydrocholesterol to pre-vitamin $\mathrm{D}_{3}$, a precursor of vitamin $\mathrm{D}$, which has a wide range of beneficial effects as reviewed by Goltzman (2) and Dixon et. al. (3). Exposure to UVR is also associated with an increase in lipid peroxidation leading to cell dysfunction or necrosis $(4 ; 5)$ destruction of skin collagen leading to photoaging (6), immunosuppression (7), and DNA damage leading to skin cancer, through either oxidative (8) or direct photochemical processes $(9 ; 10)$.

DNA has been shown to be an initial skin chromophore, with UVR absorption by DNA resulting in the formation of thymine dimers which is also the initiating step in photocarcinogenesis $(9 ; 11)$. UVB radiation is directly absorbed by pyrimidines, especially thymine, resulting in the formation of pyrimidine dimers in vitro $(12 ; 13)$. These dimers can be formed between two adjacent thymines (T-T), two adjacent cytosines (C-C) or between adjacent thymine-cytosine pairs $(\mathrm{T}-\mathrm{C})$.

Corresponding Author: Dr. Ed S. Krol; Drug Discovery and Development Research Group, College of Pharmacy and Nutrition, University of Saskatchewan, 107 Wiggins Rd, Saskatoon, SK, Canada; E-mail: ed.krol@usask.ca 
The pyrimidine dimers can take a number of forms but are most commonly found as cyclobutane pyrimidine dimers (CPD) which are formed by [2+2] cycloaddition between the C5-C6 double bonds of adjacent pyrimidines $(12 ; 14)$. Other dimers observed include 6-4 dimers (6-4) and their Dewar isomers. The relative frequency of occurrence of these dimers exposed to UV in vitro is: $\mathrm{T}-\mathrm{T}(\mathrm{CPD})>\mathrm{T}-\mathrm{C}(6-4)>\mathrm{T}-\mathrm{C}(\mathrm{CPD})>\mathrm{T}-\mathrm{T}(6-4)$ (12).

If photoinduced dimers are not repaired prior to replication, they can result in $\mathrm{C}$ to $\mathrm{T}$ and $\mathrm{CC}$ to $\mathrm{TT}$ transversions. If these mutations occur in a protein coding region, particularly in the coding region for a regulatory protein such as p53, they can lead to the formation of carcinomas $(6 ; 15)$. Yarosh, et. al. (16) demonstrated that in $\mathrm{HaCaT}$ cells UVB radiation induces the immunosuppressive cytokine TNF- $\alpha$, and that this same cytokine was induced when DNA was damaged using HindIII. The same group also showed that increased repair of CPDs by addition of $\mathrm{T} 4$ endonuclease $\mathrm{V}$, which is specific for UVR-induced DNA damage, resulted in a decrease in immunosuppression (17). Similar results have shown that in in vivo human experiments, T4 endonuclease $\mathrm{V}$ given after solar simulated radiation exposure prevented immunosuppression (18).

Exposure to UVR, particularly UVB, has also been associated with immunosuppression, both local and systemic $(6 ; 7)$. This immunosuppression is believed to reduce the risk of harmful, excessive inflammation in the skin following UVR exposure (6) and has been found to result from both acute (7) and chronic (19) exposure to UVR. UVB radiationinduced immunosuppression occurs via down regulation of T-cell mediated immunity through the induction of immunomodulating cytokines $(6 ; 20)$. UVB radiation has been shown to induce IL-10 (21;22), IL-4(22), IL-6 (23) and TNF- $\alpha$ (22).

UVR-induced photoaging is primarily associated with radiation in the UVA range and is characterized by increased wrinkle formation relative to unexposed skin, a loss of skin recoil capacity and an increase in skin fragility (24-26). Histologically, the most prominent feature of photoaged skin is solar elastosis, characterized by degradation of collagen and accumulation of abnormal elastin $(26 ; 27)$. UVA, and to a lesser extent UVB radiation, causes photoaging through induction of matrix metalloproteinase-1 (MMP-1) which is responsible for the breakdown of collagen (24;28-32). Both UVA and UVB radiation can induce the formation of reactive oxygen species (ROS) in the skin $(4 ; 33)$ and there is good evidence that it is these ROS that initiate the photoaging process.

Due to the negative effects associated with overexposure to solar UVR, a large number of topically applied sunscreens are available on the market and the development of new sunscreens is an active area of research. One of the approaches being used in the development of new sunscreen products is the incorporation of natural products produced by plants for the purpose of UVR protection (34-36). One family of natural products which is believed to have photoprotective properties in plants are the flavonols such as quercetin (3, 3', 4', 5, 7-pentahydroxyflavone Figure 1). Quercetin has absorption bands in the UV range $(256,365$ nm) (37) and both the aglycone as well as various quercetin glycosides are upregulated in response to UVR exposure in various plant species including Brassica napus (38), Petunia axillaris (39) and Malus domestica (40). Dietary intake of quercetin by mice has been shown to decrease UVR-induced immunosuppression $(41 ; 42)$ and a topical quercetin emulsion has been shown to protect against UVBinduced skin damage in a hairless mouse model (43). Quercetin can also decrease photoinduced MMP-1 production in human fibroblasts (44) and UVR-induced inflammatory cytokine production through the $\mathrm{Nf \kappa B}$ pathway in primary human keratinocytes (45). Quercetin can also protect against UVR-induced decomposition of the sunscreen octyl methoxycinnamate (46) and the anti-inflammatory drug ketoprofen (47) in vitro. However, a study demonstrating quercetin induction of apoptosis in UVB treated HaCaT cells reported that quercetin was unstable in Dulbecco's Modified Eagle Medium (DMEM) and decomposed to unknown products, although the extent of uptake of intact quercetin or decomposition products into the $\mathrm{HaCaT}$ cells was not known (48). When quercetin was stabilized with ascorbic acid the apoptotic effect was reduced, suggesting that the apoptotic effect may result from the decomposition products and ROS generated from redox cycling of the parent compound. 


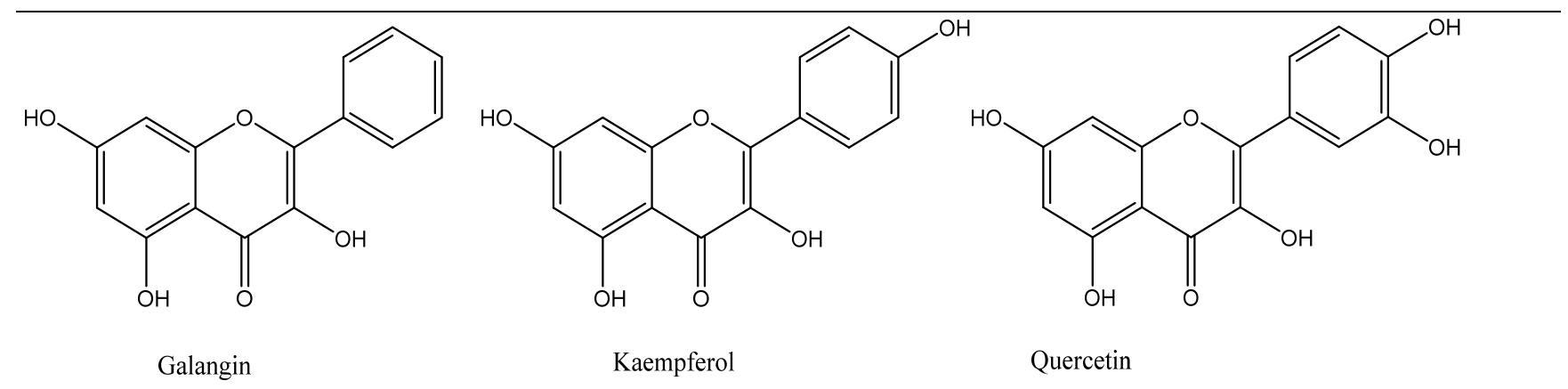

Figure 1. Structure of flavonols used in this study.

Studies on the UVR protective properties of other flavonols such as kaempferol and myricetin have also been carried out. Kaempferol has demonstrated inhibition of UVB-induced COX-2 expression through suppression of Src kinase activity in JB6 P+ cells (49). Myricetin can suppress Fyn kinase activity in JB6 P+ cells and mouse skin (50) and inhibit Akt-mediated survival signalling in UVB-exposed $\mathrm{HaCaT}$ cells (51). Myricetin was also found to decrease UVB-induced MMP-9 expression in mouse skin through the suppression of Raf (52) and PI3 kinase activity (53).

We have previously reported on the favorable antioxidant properties of quercetin in UVR-induced liposomes(54). Since quercetin displays absorbance maxima at 256 and $365 \mathrm{~nm}$, this led us to speculate that quercetin may also provide protection from UVR-induced DNA damage as a result of direct UV absorbance. We hypothesize that quercetin can protect against UVR-induced direct DNA damage in skin in vitro. To study this hypothesis we determined the ability of quercetin to prevent UVRinduced T-T (CPD) formation in the artificial skin mimic EpiDerm ${ }^{\mathrm{TM}}$ using a high performance liquid chromatography atmospheric pressure chemical ionization tandem mass spectrometric (HPLCAPCI-MS/MS) method. We have also previously reported that flavonol stability to UVA radiation is dependent on B-ring substitution, with myricetin and quercetin being the least stable and kaempferol and galangin being the most stable (55). As a result of the instability of quercetin, we also investigated the ability of kaempferol and galangin to inhibit T$\mathrm{T}$ (CPD) formation in EpiDerm ${ }^{\mathrm{TM}}$. All of the flavonols tested were able to inhibit the formation of UVB radiation induced T-T (CPD) formation and suggests that kaempferol and galangin may prove to be effective components of a topically applied sunscreen.

\section{METHODS AND MATERIALS}

\section{Chemicals}

Quercetin dihydrate $\left(\mathrm{C}_{15} \mathrm{H}_{10} \mathrm{O}_{7} .2 \mathrm{H}_{2} \mathrm{O}, \mathrm{M}_{\mathrm{W}}=338.26\right)$, kaempferol $\left(\mathrm{C}_{15} \mathrm{H}_{10} \mathrm{O}_{6}, \mathrm{M}_{\mathrm{W}}=286.23\right)$, galangin $\left(\mathrm{C}_{15} \mathrm{H}_{10} \mathrm{O} 5, \quad \mathrm{M}_{\mathrm{W}}=270.24\right)$, thymine $\left(\mathrm{C}_{5} \mathrm{H}_{6} \mathrm{~N}_{2} \mathrm{O}_{2}\right.$, minimum 99\%), 5-fluorouracil $\left(\mathrm{C}_{4} \mathrm{H}_{3} \mathrm{FN}_{2} \mathrm{O}_{2}, \geq 99 \%\right)$ and formic acid were purchased from SigmaAldrich Canada Ltd (Oakville, ON). LC/MS grade water and methanol were purchased from Fisher Scientific Canada (Ottawa, ON).

2 FS20T12/UVB lamps (National Biological Corp., Beachwood, OH) filtered to remove UVC (cellulose acetate) with an intensity of $1.3 \mathrm{~mW} \cdot \mathrm{cm}^{-2}$ at $310 \mathrm{~nm}$ as measured with a UVP UVX-31 sensor or $2 \mathrm{~F} 20 \mathrm{~T} 12 / \mathrm{BL} / \mathrm{HO}$ UVA lamps (National Biological Corp., Beachwood, $\mathrm{OH}$ ) filtered to remove UVC with an intensity of $0.74 \mathrm{~mW} \cdot \mathrm{cm}^{-2}$ at $365 \mathrm{~nm}$ as measured with a UVP UVX-36 sensor were used for irradiation.

EpiDerm $^{\mathrm{TM}}$ skin mimics and media were purchased from MatTek Corporation, (Ashland, MA). Quantikine ${ }^{\circledR}$ Human pro-MMP-1 ELISA kits and Quantikine ${ }^{\circledR}$ Human TNF- $\alpha /$ TNFSF1A ELISA kits were purchased from Cedarlane Laboratories Ltd., (Burlington, ON) and read using a Synergy HT Multi-Detection Microplate Reader (BioTek Instruments Inc., Winooski, VT). DNeasy Blood \& Tissue Kits were purchased from Qiagen (Toronto, $\mathrm{ON})$.

\section{Cyclobutane thymine photodimer analysis} Preparation of Cyclobutane thymine photodimer standard

Cyclobutane thymine photodimer (T-T (CPD)) was prepared in water using the method of Ramsey and 
Ho (56). An aqueous solution of thymine at a concentration of $2 \mathrm{mM}$ was frozen and then exposed to UVC light in a reactor for $30 \mathrm{~min}$. Following the irradiation, the frozen sample was thawed in water bath at $40{ }^{0} \mathrm{C}$. The 'freezeirradiation-thaw' process was repeated five times daily for 10 days to prepare the standard.

Isolation of the T-T (CPD) was carried out using reversed-phase HPLC on a Waters Alliance system (Waters Corp., Milford, MA) which consisted of a pump, autosampler, and photodiode array detector (Waters 2996). Elution of T-T (CPD) was carried out on an Allsphere ODS-2, $3 \mu$ column $(2.1 \mathrm{~mm} \times 150 \mathrm{~mm})$ with isocratic flow of $99 \%$ water/ $1 \%$ methanol with $0.1 \%$ formic acid at a flow rate of $200 \mu \mathrm{L} / \mathrm{min}$. Data was processed using Waters Empower software.

The separation and isolation of cyclobutane thymine dimer was performed using semipreparative reversed-phase HPLC using the same Waters system as above with an Allsphere ODS-2 $5 \mu$ column $(10 \mathrm{~mm} \times 300 \mathrm{~mm})$. A gradient elution was carried out consisting of water and methanol with $0.1 \%$ formic acid at a flow rate of $3 \mathrm{ml} / \mathrm{min}$. The gradient for T-T (CPD) collection was as follows: 0 to $15 \mathrm{~min}$, linear gradient from $100 \% \mathrm{~A}$ to $90 \% \mathrm{~A} ; 15$ to $18 \mathrm{~min}$, isocratic $90 \% \mathrm{~A} ; 18$ to 19 min, linear gradient from $90 \%$ A to $100 \% \mathrm{~A} ; 19$ to $20 \mathrm{~min}$, isocratic $100 \% \mathrm{~A}$. Aliquots of $100 \mu \mathrm{L}$ were injected onto the column and T-T (CPD) $\left(\mathrm{R}_{\mathrm{t}}=14.4\right.$ $\mathrm{min})$ was collected using a fraction collector. The column was maintained at room temperature $\left(22^{\circ} \mathrm{C}\right)$ and washed with (50:50) water: methanol after every use. Collected fractions were combined and the solvent removed via freeze drying (Labconco Freezone 6 Plus, Labconco Corp., Kansas City, MO). Stock solutions $(100 \mu \mathrm{M})$ were prepared by dissolving known amounts of T-T (CPD) in 100\% water. The cyclobutane dimer is reported to be the major photoproduct isolated ( $85-90 \%)$ under these conditions (56), consistent with our results, and APCI-MS/MS results $(m / z 253 \rightarrow 210$ and $m / z 253$ $\rightarrow 139$ ) were consistent with CPD formation.

\section{HPLC-APCI-MS/MS analysis}

HPLC-MS/MS analysis was carried out at room temperature on an Agilent 1100 system coupled to an AB SCIEX 4000 QTRAP (AB SCIEX, Vaughn, $\mathrm{ON})$ quadrupole linear ion trap mass spectrometer. The HPLC system consisted of a pump (Agilent $1100 \mathrm{G} 1311 \mathrm{~A}$ ) and an autosampler (Agilent 1100 G1329A) (Agilent Technologies, Mississauga, ON).
HPLC flow was diverted to waste for the first 2 minutes of each run through an electronic vaco valve, and then from 13 to $20 \mathrm{~min}$ when no data acquisition was taking place. Aliquots of $10 \mu \mathrm{L}$ of processed samples were injected onto an ODS-2 $3 \mu$ column $(2.1 \mathrm{~mm} \times 100 \mathrm{~mm})$. The column and autosampler were maintained at room temperature. The analytes were eluted under isocratic flow of $99 \%$ water/ $1 \%$ methanol with $0.1 \%$ formic acid at a flow rate of $200 \mu \mathrm{L} / \mathrm{min}$ with a run time of $20 \mathrm{~min}$.

The mass spectrometer was used in multiple reaction monitoring (MRM) mode, equipped with a heated nebulizer (Atmospheric pressure chemical ionization (APCI)) interface used in positive mode. The precursor and product ion spectra was determined by direct infusion of standard and internal standard into the ion source with a syringe pump. Quantitative analysis of the processed samples was performed using sum of two MRM transitions for the standard (T-T (CPD)) from $\mathrm{m} / \mathrm{z}$ $253 \rightarrow 210$ and $m / z 253 \rightarrow 139$. For the internal standard (5-fluorouracil) the Q1/Q3 transition was monitored from $m / z 131 \rightarrow 114$.

All of the mass spectrometry conditions for ionization of the standard and internal standard were optimized by direct infusion using a syringe pump at a flow rate of $10 \mu \mathrm{L} / \mathrm{min}$. Nitrogen was used as the nebulizer, collision and curtain gas. The optimized mass spectrometer parameters were as follows: curtain gas 45psi, collision-activated dissociation (CAD) 5psi, nebulizer gas (GS1) 40psi, entrance potential (EP) $10 \mathrm{eV}$ and temperature $450^{\circ} \mathrm{C}$. The optimized APCI-MS/MS parameters are given in table 1. Analyst 1.5.1 software from AB SCIEX was used for controlling the equipment and acquiring and processing of data.

\section{Preparation of stock and working standard solutions of T-T (CPD)}

All of the primary and working stock solutions of standard T-T (CPD) and that of internal standard (5fluorouracil) were prepared in LC-MS grade water. $100 \mu \mathrm{M}$ primary stock solutions of standard and internal standard were prepared in water and stored at $-20^{\circ} \mathrm{C}$. The 10 times concentrated working stock solutions of standard and quality control samples were made by serial dilution of primary stock solution in water. Our QC samples including low quality control (LQC), middle quality control (MQC) and high quality control (HQC) were prepared as per United States Food and Drug Administration (USFDA) guidelines with 
concentrations of $0.05 \mu \mathrm{M}, 0.25 \mu \mathrm{M}$, and $0.5 \mu \mathrm{M}$ respectively. The LQC is 3-times the lower limit of quantitation (LLOQ) and HQC is $80 \%$ of the upper limit of quantitation. The stocks stored at $-20^{\circ} \mathrm{C}$ were used to prepare fresh standard curve and quality control samples on each day of analysis.

\section{Ultraviolet Radiation Exposure}

We carried out a pilot study in cultured keratinocytes ( $\mathrm{HaCaT}$ cells) to determine an appropriate concentration range for quercetin in our EpiDerm $^{\mathrm{TM}}$ studies. The ability of quercetin to prevent UVA and UVB induced production and/or release of MMP-1 and TNF- $\alpha$ from $\mathrm{HaCaT}$ cells was assessed. $\mathrm{HaCaT}$ cells were pre-treated with, $50 \mu \mathrm{M}, 100 \mu \mathrm{M}$ and $200 \mu \mathrm{M}$ quercetin in media 24 $\mathrm{h}$ prior to either UVA or UVB exposure.

\section{EpiDerm $^{\mathrm{TM}}$ Skin Mimics}

EpiDerm $^{\mathrm{TM}}$ artificial skin mimics (EPI-200 and EPI-606) were used as per the supplier's instructions. EPI-200 and EPI-606 tissues differ in their surface area, EPI-200 tissues have a diameter of $9 \mathrm{~mm}$ and EPI-606 tissues have a diameter of 22 $\mathrm{mm}$. Upon receipt of an EpiDerm ${ }^{\mathrm{TM}}$ shipment, the tissues were handled as per the protocol provided. Briefly, individual tissues from EPI-200 were placed in each well of a 6-well culture plate along with $1 \mathrm{~mL}$ of maintenance media. Similarly, EPI606 tissues on the day of shipment were placed in $100 \mathrm{~mm}$ petri dishes containing $6.3 \mathrm{ml}$ of maintenance media. The tissues were incubated at $37^{\circ} \mathrm{C}$ with $5 \% \mathrm{CO}_{2}$ overnight to recover from the stress of the shipment. Following incubation, the maintenance media was replaced with assay media for UVR exposure.

Pilot Study. UV irradiation of EpiDerm ${ }^{\mathrm{TM}}$ EPI200: MMP-1, TNF- $\alpha$ analysis

EpiDerm ${ }^{\mathrm{TM}}$ EPI-200 samples were treated topically with $50 \mu \mathrm{L}$ and $100 \mu \mathrm{L}$ of $26 \mu \mathrm{M}$ quercetin (1 nmol, 2 nmol respectively) in acetone immediately prior to UVR exposure. The amount of quercetin used was calculated to be the same mass of quercetin delivered on to the skin per $\mathrm{cm}^{2}$ as was delivered to $\mathrm{HaCaT}$ cells of concentrations of 100 $\mu \mathrm{M}$ and $200 \mu \mathrm{M}$ (unpublished data). Following application, samples were left for $10 \mathrm{~min}$ to allow the acetone to evaporate, leaving a thin layer of quercetin on the skin sample prior to UVR exposure. For UVB exposure samples were then placed under 2 FS20T12/UVB lamps (National
Biological Corp., Beachwood, OH) and irradiated for $30 \mathrm{~min}$ for a total dose of $9000 \mathrm{~J} / \mathrm{m}^{2}$ at $310 \mathrm{~nm}$. For UVA exposure, cells were placed under 2 F20T12/BL/HO UVA lamps (National Biological Corp., Beachwood, OH) and irradiated for $240 \mathrm{~min}$ for a total dose of $100 \mathrm{~kJ} / \mathrm{m}^{2}$ at $365 \mathrm{~nm}$. Following exposure, samples were returned to the incubator at $37^{\circ} \mathrm{C}$ with $5 \% \mathrm{CO}_{2}$. Cell cultures were removed from the incubator 24 hours after exposure and media collected and placed in a $-80^{\circ} \mathrm{C}$ freezer for later analysis. Experiments were performed in duplicate on three separate occasions.

\section{pro-MMP-1 Analysis}

Extracellular pro-MMP-1 produced in response to UVR in the presence or absence of quercetin was measured using a Quantikine ${ }^{\circledR}$ Human pro-MMP-1 ELISA kit (R\&D Systems, Minneapolis, MN) following the manufacturer's directions. Briefly, $100 \mu \mathrm{L}$ of culture media and $100 \mu \mathrm{L}$ of diluent solution were added to each well of a 96-well plate and shaken at room temperature for 2 hours. The samples were aspirated, the plate was washed four times and $200 \mu \mathrm{L}$ of conjugate was added to each well and the plate shaken at room temperature for 2 hrs. Conjugate solution was aspirated, the plate was washed four times and $200 \mu \mathrm{L}$ of substrate solution was added to each well followed by a $20 \mathrm{~min}$ incubation protected from light. $50 \mu \mathrm{L}$ of stop solution was then added to each well and the absorbance at $450 \mathrm{~nm}$ and $570 \mathrm{~nm}$ was recorded using a BioTek Instruments (Winooski, VT) plate reader. An eight point calibration curve was prepared using standards provided by the supplier and the pro-MMP-1 concentration of each well was determined by interpolation. Results are reported as mean \pm standard deviation.

\section{TNF-a Analysis}

Extracellular TNF- $\alpha$ produced in response to UVR in the presence or absence of quercetin was measured using a Quantikine $^{\mathbb{R}}$ Human TNF$\alpha /$ TNFSF1A ELISA kit (R\&D Systems, Minneapolis, MN) following the manufacturer's directions. Briefly, $50 \mu \mathrm{L}$ of culture media and 200 $\mu \mathrm{L}$ of diluent solution were added to each well of a 96-well plate and incubated at room temperature for 2 hours. The samples were aspirated, the plate was washed four times and $200 \mu \mathrm{L}$ of conjugate was added to each well and the plate incubated at room temperature for 1 hour. Conjugate solution was aspirated, the plate was washed four times and 200 
$\mu \mathrm{L}$ of substrate solution was added to each well followed by a $20 \mathrm{~min}$ incubation protected from light. $50 \mu \mathrm{L}$ of stop solution was then added to each well and the absorbance at $450 \mathrm{~nm}$ and $570 \mathrm{~nm}$ was recorded using a BioTek Instruments (Winooski, VT) plate reader. An eight point calibration curve was prepared using standard provided by the supplier and the TNF- $\alpha$ concentration of each well was determined by interpolation. Results are reported as mean \pm standard deviation.

\section{EpiDerm $^{\mathrm{TM}}$ EPI-606: T-T (CPD) Analysis}

EpiDerm ${ }^{\mathrm{TM}}$ EPI-606 samples were treated topically with $300 \mu \mathrm{L}$ of $52 \mu \mathrm{M}(15 \mathrm{nmol})$ flavonol (quercetin, kaempferol, galangin) in acetone for a final concentration of $4 \mathrm{nmol} / \mathrm{cm}^{2}$ immediately prior to UVR exposure. Following application of the flavonol in acetone, samples were left for $10 \mathrm{~min}$ to allow acetone to evaporate leaving a thin layer of flavonol on the skin prior to UVR exposure. For UVB exposure, samples were placed under 2 FS20T12/UVB lamps (National Biological Corp., Beachwood, $\mathrm{OH}$ ) and irradiated at $310 \mathrm{~nm}$ for a dose of $0.05 \mathrm{~J} / \mathrm{cm}^{2}$. For UVA exposure, cells were placed under 2 F20T12/BL/HO UVA lamps (National Biological Corp., Beachwood, $\mathrm{OH}$ ) and irradiated at $365 \mathrm{~nm}$ for a dose of $8.5 \mathrm{~J} / \mathrm{cm}^{2}$. For both UVA and UVB irradiations, the output of the lamps was filtered to remove UVC radiation. Positive controls consisted of vehicle without flavonol. For the dark controls, plates were wrapped in aluminum foil and placed under the lamps for similar exposure times to account for heating effects. Following irradiation, the tissues were washed with PBS, and were carefully removed from the tissue culture inserts and placed in a $-80^{\circ} \mathrm{C}$ freezer for later analysis. All doses were performed in duplicate for three different days.

\section{Preparation of samples for T-T (CPD) analysis}

DNA was extracted from each of the treated, control, and dark tissue samples by using a DNeasy kit. The tissues were incubated at $56^{\circ} \mathrm{C}$ in the presence of ATL buffer and proteinase $\mathrm{K}$ for 4 hours for tissue lysis. After lysis the remaining steps were performed as per the protocol of the DNeasy kit, except that in the final step DNA was eluted from the spin columns by twice washing with $200 \mu 1$ of water. For each tissue sample, three extraction columns were used.

After isolation of DNA, the combined eluant from three columns was spiked with $20 \mu \mathrm{L}$ of working stock solution including internal standard. Each sample was subjected to hydrolysis in $2.4 \mathrm{ml}$ of $88 \%$ formic acid at $125^{\circ} \mathrm{C}$ for $20 \mathrm{~min}$. The hydrolysate of all the treated, control and dark samples was evaporated and resuspended in $100 \mu \mathrm{L}$ of water. The samples were vortex-mixed for $30 \mathrm{sec}$ and injected into the HPLC-MS/MS system with an injection volume of $80 \mu \mathrm{L}$.

\section{Preparation of T-T (CPD) calibration curves}

The standard curve $(\mathrm{n}=2)$ and three quality control $(n=2)$ samples were prepared fresh on the day of analysis. Similarly, DNA was extracted from blank unexposed EpiDerm ${ }^{\mathrm{TM}}$ using the DNeasy kit as described above. After DNA isolation, the combined eluants from three columns were spiked with $20 \mu \mathrm{L}$ of working stock solution of standard/quality control and internal standard. Each sample was subjected to hydrolysis in $200 \mu \mathrm{L}$ of $88 \%$ formic acid at $125^{\circ} \mathrm{C}$ for $20 \min (57)$. The hydrolysate of all the standard, quality control and blank samples were evaporated and re-suspended in $100 \mu \mathrm{L}$ of water. The samples were vortex-mixed for $30 \mathrm{sec}$ and injected into the HPLC-MS/MS system using an injection volume of $80 \mu \mathrm{L}$.

\section{Quercetin Stability}

The stability of quercetin which was topically applied to the EpiDerm ${ }^{\mathrm{TM}}$ tissues was also assessed. Following UVA or UVB exposure $100 \mu \mathrm{L}$ of acetone was placed on the EpiDerm ${ }^{\mathrm{TM}}$ samples and allowed to re-dissolve the UVR exposed quercetin and photoproducts. The acetone was then collected and analyzed by HPLC-PDA as described previously (58).

\section{STATISTICAL METHODS}

Statistical analyses were performed using GraphPad Prism 5.0 (GrpahPad Software Inc., La Jolla, CA). Data was analyzed by one-way ANOVA with a Bonferroni's Multiple Comparison Test. The level of significance was set at $\mathrm{P}<0.05$.

\section{RESULTS}

Effect of Quercetin on MMP-1 and TNF- $\alpha$ production in UVR treated EpiDerm ${ }^{\mathrm{TM}}-200$.

We used HaCaT cells in a pilot study to confirm that we were using sufficiently high UV doses to cause both MMP-1 release and TNF- $\alpha$ production, and concentrations of quercetin that could have an 
effect on either MMP-1 or TNF- $\alpha$ levels for subsequent EpiDerm ${ }^{\mathrm{TM}}$ studies. We observed that $9000 \mathrm{~J} / \mathrm{m}^{2}$ (UVB) or $100 \mathrm{~kJ} / \mathrm{m}^{2}$ (UVA) was sufficient to cause increased MMP-1 and TNF- $\alpha$ levels vs dark control. When we treated the HaCaT cells with $100 \mu \mathrm{M}$ and $200 \mu \mathrm{M}$ quercetin, we observed a significant decrease in the amount of MMP-1 released relative to both vehicle control (DMSO) and untreated cells (See Supplementary material). Pre-treatment of $\mathrm{HaCaT}$ cells with quercetin at any of the concentrations used did not result in a significant decrease in TNF- $\alpha$ production.

The effectiveness of flavonols as photoprotectants was assessed by treating the artificial skin mimic EpiDerm ${ }^{\mathrm{TM}}$ EPI-200 with quercetin. We applied quercetin topically to the stratum corneum of EpiDerm ${ }^{\mathrm{TM}}$ EPI-200 immediately prior to UVR exposure. The effect of topical quercetin treatment of EpiDerm ${ }^{\mathrm{TM}}$ EPI-200 on MMP-1 excretion is presented in Figure 2. Both
UVA and UVB exposed samples treated with the equivalent of either $1 \mathrm{nmol}(100 \mu \mathrm{M})$ or $2 \mathrm{nmol}$ $(200 \mu \mathrm{M})$ quercetin resulted in a significant decrease in MMP-1 production compared to control. Notably, for both UVA and UVB exposed EpiDerm ${ }^{\mathrm{TM}}$ EPI-200 treated with 2 nmol quercetin, extracellular production of MMP-1 decreased to the level seen in non-UVR exposed skin mimics (dark control).

Figure 3 shows the effects of topical quercetin treatment of EpiDerm ${ }^{\mathrm{TM}}$ EPI-200 on the production of TNF- $\alpha$. For both UVA and UVB treated EpiDerm $^{\mathrm{TM}}$ we observed significant decreases in TNF- $\alpha$ production at $1 \mathrm{nmol}$, and a further reduction of TNF- $\alpha$ production to dark control levels in those skin mimics treated with 2 nmol quercetin. For the UVA exposed samples, we observed a reduction to dark control levels of TNF$\alpha$ with both the $1 \mathrm{nmol}$ and $2 \mathrm{nmol}$ quercetin treatments.

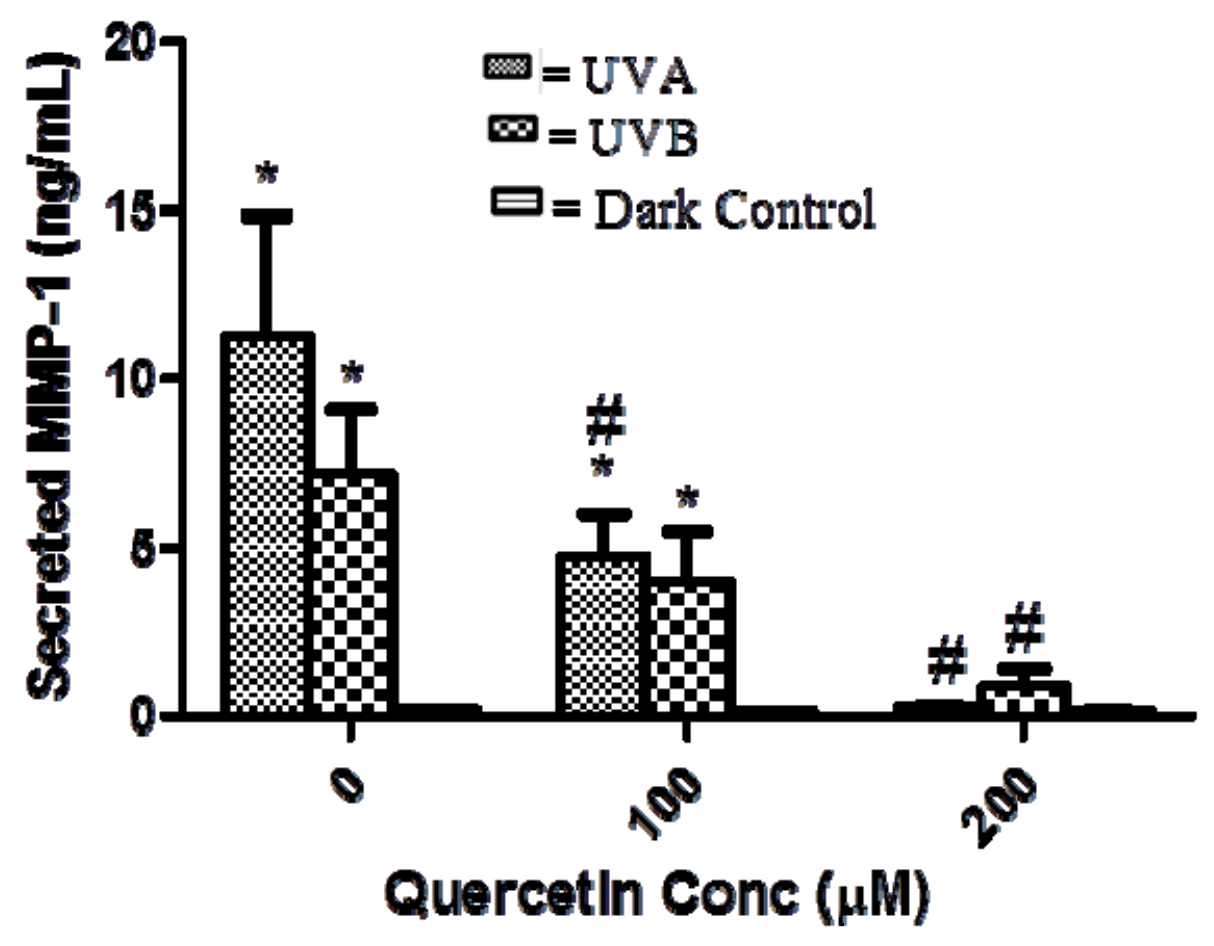

Figure 2. Quercetin prevention of MMP-1 production by EpiDerm ${ }^{\mathrm{TM}}$ EPI-200 skin mimics exposed to either $10 \mathrm{~J} / \mathrm{cm}^{2}$ UVA, $0.9 \mathrm{~J} / \mathrm{cm}^{2} \mathrm{UVB}$ (in open culture dishes, UVC removed by filtration) or no UVR (dark) by ELISA. The EPI-200 cells were treated with quercetin in acetone, which was allowed to evaporate, immediately prior to UVR exposure leaving a thin film of quercetin. Following treatment skin mimics were returned to the incubator. Media was collected for MMP-1 analysis 24 hours later and stored at $-80^{\circ} \mathrm{C}$ until analysis. $*=$ significantly different from dark control $(\mathrm{p}<0.05), \#=$ significantly different from control $(\mathrm{p}<0.05)$. 
Effect of Flavonols on Cyclobutane Thymine dimer formation in UVR treated EpiDerm ${ }^{\mathrm{TM}}$ EPI-606.

\section{LC-MS/MS analysis}

We initially tested two ionization sources, ESI and APCI, and determined that APCI was a superior ionization method to ESI as the sensitivity of APCI for T-T (CPD) was an order of magnitude greater (data not shown). The detection and quantitation of T-T (CPD) was achieved by optimizing mass spectrometric conditions operated in positive mode. T-T (CPD) was monitored for two fragment ions with $\mathrm{m} / \mathrm{z} \quad 253 \rightarrow 210$ and $\mathrm{m} / \mathrm{z} \quad 253 \rightarrow 139$ (Figure 4), which are specific for the cyclobutane thymine dimer.

We used an internal standard in our experiments to account for the undesired effects of sample preparation, matrix effects and instrument error. Isotopically labeled internal standards would be a superior option; however, these are not commercially available for thymine dimer. 5-FU was selected as an internal standard because of its structural similarity with thymine, its elution within the same chromatographic time frame, and most importantly, 5-FU does not occur naturally. 5-FU was monitored with Q1/ Q3 transition of $m / z$ $131 \rightarrow 114$.

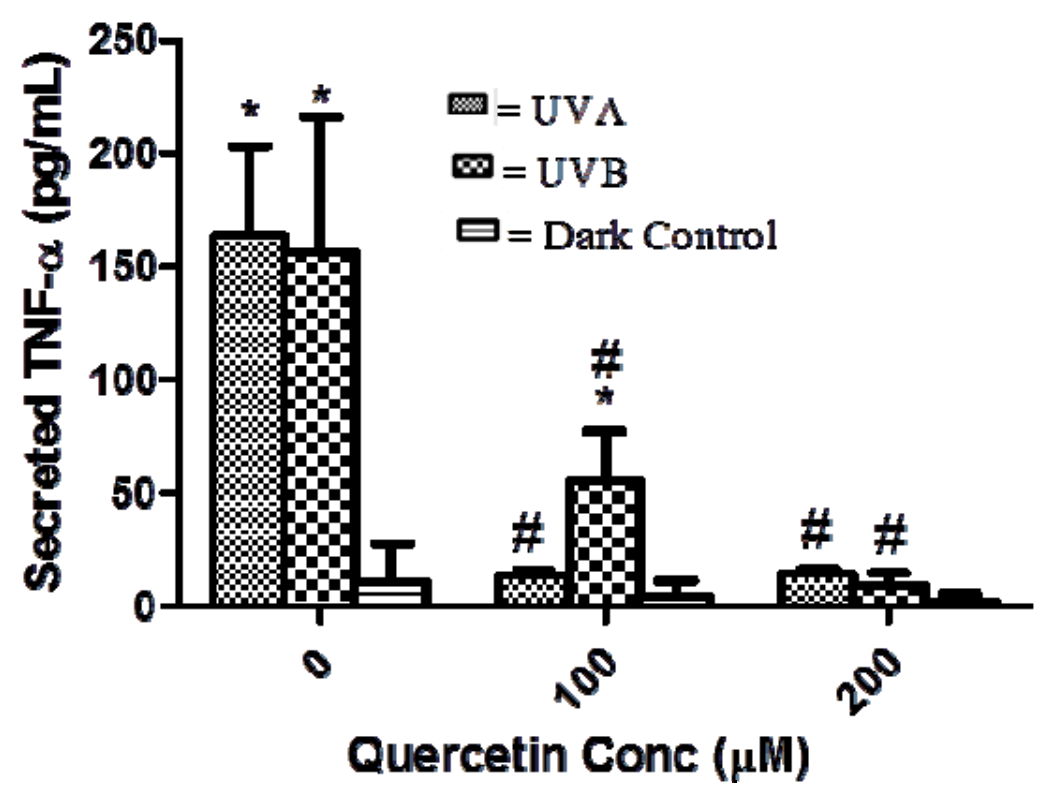

Figure 3. Quercetin prevention of TNF- $\alpha$ production by EpiDerm ${ }^{\mathrm{TM}}$ EPI-200 skin mimics exposed to either $10 \mathrm{~J} / \mathrm{cm}^{2} \mathrm{UVA}$, $0.9 \mathrm{~J} / \mathrm{cm}^{2} \mathrm{UVB}$ (in open culture dishes, UVC removed by filtration) or no UVR (dark) by ELISA. The EPI-200 cells were treated with quercetin in acetone, which was allowed to evaporate, immediately prior to UVR exposure leaving a thin film of quercetin. Following treatment skin mimics were returned to the incubator. Media was collected for TNF- $\alpha$ analysis 24 hours later and stored at $-80^{\circ} \mathrm{C}$ until analysis. ${ }^{*}=$ significantly different from dark control $(\mathrm{p}<0.05)$, \# = significantly different from control $(\mathrm{p}<0.05)$.

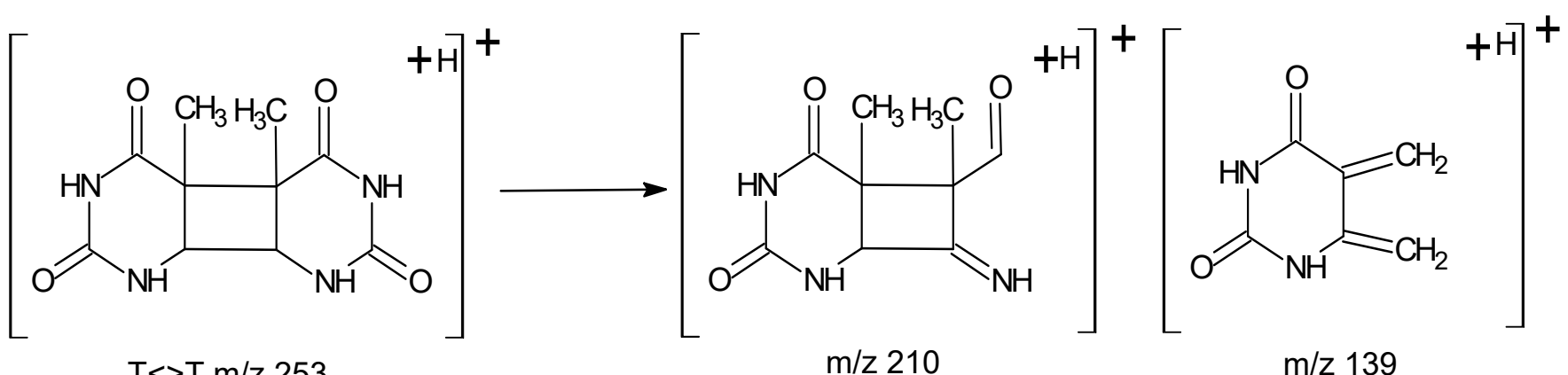

Figure 4. Structural representation of product ions of cyclobutane thymine dimer with $\mathrm{m} / \mathrm{z}$ transition (a) $253 \rightarrow 210$ $253 \rightarrow 139$ 


\section{Retention times}

The standard (T-T (CPD)) and internal standard (5-FU) were efficiently separated from thymine using reversed phase HPLC. Under our chromatographic conditions, T-T (CPD) and 5-FU eluted at retention times of $6.83 \mathrm{~min}$ and $4.07 \mathrm{~min}$ respectively. The extracted ion chromatogram of spiked samples corresponding to internal standard $(\mathrm{m} / \mathrm{z} 131 \rightarrow 114)$ and standard $(\mathrm{m} / \mathrm{z} 253 \rightarrow 210$ and $\mathrm{m} / \mathrm{z} 253 \rightarrow 139)$ are shown in Figure 5 .

(A)
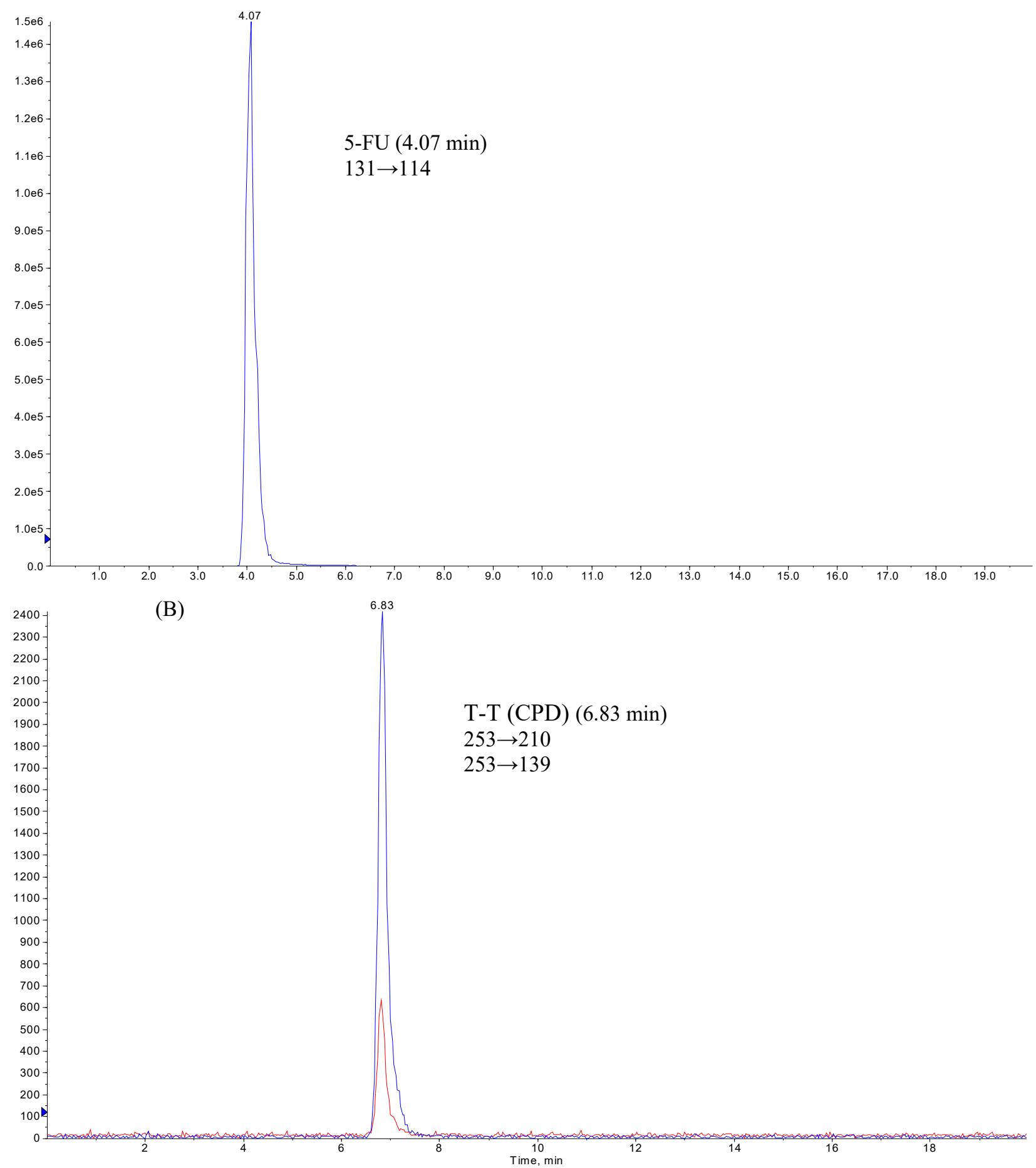

Figure 5. Extracted total ion chromatograms for spiked sample corresponding to (A) internal standard (5-FU) with $\mathrm{m} / \mathrm{z}$ $131 \rightarrow 114$ and (B) standard (T-T (CPD)) with $\mathrm{m} / z 253 \rightarrow 210$ and $253 \rightarrow 139$. 
The effect of topical application of a range of flavonols on T-T (CPD) formation in reconstructed human skin models is presented in Figure 6. We treated EpiDerm ${ }^{\mathrm{TM}}$ EPI-606 topically with the flavonols quercetin, kaempferol and galangin in acetone in the same manner as for the EpiDerm ${ }^{\mathrm{TM}}$ EPI-200 experiments. It was necessary for us to utilize the larger EPI-606 skin mimics as we determined from preliminary UVA/B control irradiations of EpiDerm ${ }^{\mathrm{TM}}$ EPI-200, that T-T (CPD) levels were below the lower limit of quantitation for our LC-APCI-MS/MS method. The larger total area of the EPI-606 skin mimics allows for a greater number of T-T (CPD) to be formed. UVB exposed samples treated with $4 \mathrm{nmol} / \mathrm{cm}^{2}$ of flavonol resulted in a significant decrease in T-T (CPD) formation compared to UVB exposed control. The levels of T-T (CPD) formation in UVB exposed control and flavonol treated skin samples was significantly different from non-UVR exposed skin mimics (dark control). The levels of T-T (CPD) formation however in galangin, kaempferol and quercetin treated samples are not significantly different from each other. The same study was also performed for UVA exposed EpiDerm ${ }^{\mathrm{TM}}$ EPI-606, however the levels of T-T (CPD) formation in both control and flavonol treated samples were again below our lower limit of quantitation (data not shown).

\section{DISCUSSION}

A number of studies have suggested that flavonols such as quercetin may be effective photoprotective agents. We investigated the topical photoprotective ability of three flavonols to inhibit UV radiationinduced damage to the artificial skin mimic EpiDerm $^{\mathrm{TM}}$. To accomplish this goal we employed several biomarkers of UVR induced damage: MMP-1 secretion as a marker of ROS mediated damage and photoaging effects, cyclobutane thymine dimer (T-T (CPD)) formation as a marker of direct UV damage to DNA, and TNF- $\alpha$ as a marker of photo-immunosuppression and photodamage to DNA.

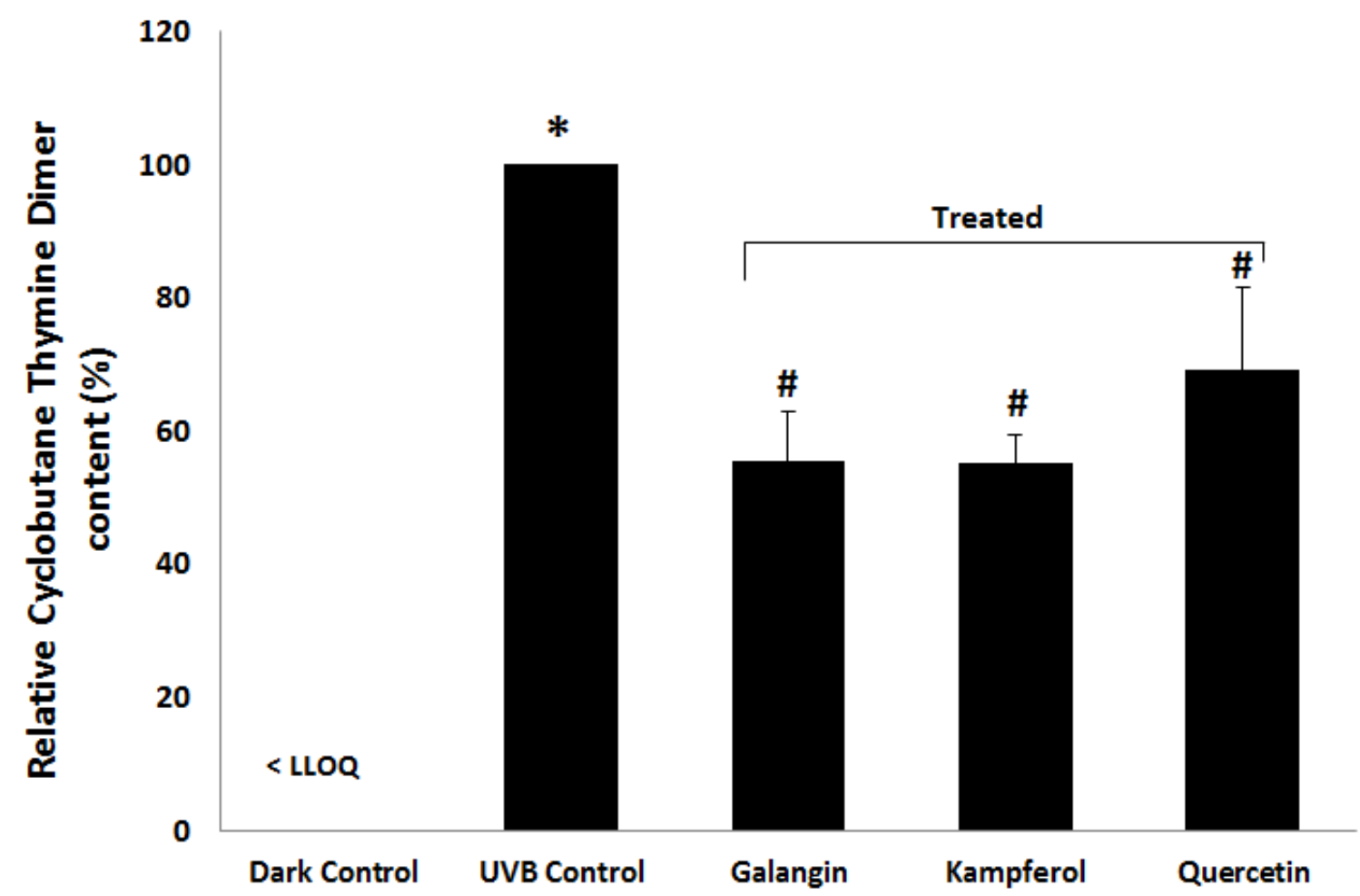

Figure 6. The graph represents the mean levels of relative content $(\%)$ of cyclobutane thymine dimer $\left( \pm\right.$ SD) in EpiDerm ${ }^{\mathrm{TM}}$ EPI-606 skin mimics exposed to $0.05 \mathrm{~J} / \mathrm{cm}^{2}$ UVB. The results indicate a decrease in relative content of cyclobutane thymine dimer in flavonol treated human skin models compared to control. The statistically significant differences $(\mathrm{p}<0.05)$ between groups are indicated by labels containing different symbols. The results containing labels with the same symbols are not significantly different. 
Topical application relies primarily on photoabsorptive processes and intercellular and cellular membrane antioxidant activity to provide photoprotection. This is in contrast to other studies in the literature where cell culture systems were used in which quercetin or other flavonols were able to fully incorporate into the cell allowing for possible effects on cell signalling and intracellular antioxidant activity (59-61).

Vicentini (62) demonstrated that quercetin (66 $\mu \mathrm{M})$ suppressed the UVR-induced NFкB pathway in primary human keratinocytes, including TNF- $\alpha$ mRNA expression, but did not reduce MMP-1 mRNA levels. Their study differed from ours in two ways: mRNA expression of MMP-1 and TNF- $\alpha$ was examined at various time-points up to $24 \mathrm{hr}$, whereas our studies examined MMP-1 and TNF- $\alpha$ protein levels at a single time point $(24 \mathrm{hr}$ post exposure); second, we determined that $50 \mu \mathrm{M}$ quercetin was insufficient to reach a significant decrease in MMP-1 activity, although we observed a trend towards decreased MMP-1. Inspection of the data in Vicentini's study at $66 \mu \mathrm{M}$ quercetin (62) suggests a similar trend in the $24 \mathrm{hr}$ data for the MMP-1 mRNA and no significant difference in TNF- $\alpha$ mRNA at $24 \mathrm{hr}$ post exposure. Unfortunately, the stability of quercetin in their cell culture system is unknown. Decomposition of quercetin could conceivably influence their results. Quercetin would have only undergone minimal absorption by our artificial skin system and without a prolonged exposure to media would be expected to undergo minimal decomposition. Our assessment of the photodegradation of quercetin applied topically to EpiDerm ${ }^{\mathrm{TM}}$ EPI-200 shows that quercetin is the major component recovered, with only trace amounts of the decomposition product quercetin depside (58) present (data not shown). Thus, the instability of quercetin reported in other cell culture systems was not observed by us in the EpiDerm $^{\text {TM }}$ EPI-200 system.

The quercetin-mediated concentrationdependent decrease in MMP-1 and TNF- $\alpha$ secretion seen in our EpiDerm ${ }^{\mathrm{TM}}$ EPI-200 study could result from either antioxidant activity or direct photoabsorption. We note that these results should be viewed with caution as EPI-200 is composed of keratinocytes and UV-induced MMP-1 formation is largely mediated through fibroblasts, although MMP-1 can be derived from UV exposed keratinocytes through an indirect pathway (63). MMP-1 induction by UVA and UVB radiation has been shown to be caused by the formation of ROS at the cell surface $(4 ; 33 ; 64 ; 65)$. As a result, both the absorbed and surface quercetin would be able to prevent initiation of MMP-1 secretion by preventing the formation of ROS at the surface of the cell, as was seen in this study. Our previous studies on UVR-induced decomposition of quercetin (58) as well as other oxidation studies (66) suggest that ${ }^{1} \mathrm{O}_{2}$ may interact with quercetin and this scavenging of ${ }^{1} \mathrm{O}_{2}$ may contribute to the quercetin-mediated reduction in MMP-1 production (67).

Quercetin may also act as a direct UVR screen, absorbing UVR and dissipating energy before ROS can be generated (note: quercetin was used at concentrations below those known to generate ROS in the presence of UVR). We anticipate that under our conditions this absorptive effect would be localized to the surface of the skin in the EpiDerm ${ }^{\mathrm{TM}}$ EPI-200 samples. The photoprotective effect we observed appears comparable against both UVB and UVA radiation. This is despite the observation that the absorbance spectrum of quercetin has a $\lambda_{\max }$ in the UVA region $(365 \mathrm{~nm}, \varepsilon=$ $28,400 \mathrm{M}^{-1} \mathrm{~cm}^{-1}$ ) and a low extinction coefficient in the UVB region. This suggests to us the ability of quercetin to prevent MMP-1 secretion appears be an antioxidant effect, although this would be expected to be limited due to minimal uptake by EPI-200.

Minimal flavonol absorption by EPI-200 suggests to us that it is unlikely quercetin interferes with the signalling pathways activated following UVR exposure (22) leading to TNF- $\alpha$ secretion. TNF- $\alpha$ is known to be formed as a result of the formation of thymine dimers by a UVR-induced photo-reaction $(17 ; 18)$. This is a direct photoreaction caused by absorption of light by DNA, primarily thymine $\left(\lambda_{\max }=264 \mathrm{~nm}\right)$, and does not go through a ROS intermediate. DNA damage caused by reaction with ROS results in the formation of DNA lesions distinct from thymine dimers which have not been shown to result in TNF- $\alpha$ production. It is tempting for us to propose that the major protective mechanism for prevention of TNF- $\alpha$ secretion in EpiDerm ${ }^{\mathrm{TM}}$ EPI-200 is direct UVR absorption by quercetin. However, we observed a large reduction in TNF- $\alpha$ production from UVA radiation, which produces fewer T-T (CPD) than UVB, suggesting that additional pathways contribute to TNF- $\alpha$ production. 
In our previous study, we established that the general pattern of flavonol photostability follows the trend galangin $>$ kaempferol $>$ quercetin which demonstrated that the number of B-ring hydroxyl groups is inversely related to flavonol stability in UVA radiation (55). We hypothesised that the ability of flavonols to protect against UVR induced damage would be inversely proportional to hydroxyl group substitution on the B-ring. A HPLC-APCI-MS/MS analytical method was developed to measure the decrease in T-T (CPD) formation in a UV irradiated reconstructed human skin model, allowing us to determine the relative sunscreening abilities of these flavonols.

Our results showed that quercetin, kaempferol and galangin applied topically to EpiDerm ${ }^{\mathrm{TM}}$ EPI606 are effective in preventing the production of T$\mathrm{T}$ (CPD). The decrease in T-T (CPD) formation indicates that quercetin, kaempferol and galangin reduce direct DNA damage caused by UVB radiation and suggest that the flavonols can act as sunscreen agents by direct absorption of UVradiation. An obvious limitation with this method is the sensitivity as we were unable to measure UVA radiation induced damage in EpiDerm ${ }^{\mathrm{TM}}$ samples and UVB radiation induced damage only for the larger EPI-606. We plan to investigate other methods for T-T (CPD) measurement to improve our analytical sensitivity. We also note that we did not normalize to total DNA extracted in our studies; for both EPI-200 and EPI-606 we report T-T (CPD) per well. We recognize this limitation, however we are confident in our results due to the consistency of our replicate experiments.

We used the artificial skin mimic EpiDerm ${ }^{\mathrm{TM}}$ as a model system to investigate flavonols as topical skin photoprotectants, in an effort to avoid problems of flavonol instability in cell media $(48 ; 55)$. Using this reconstructed human skin model, we have demonstrated that topically applied quercetin decreases three markers (MMP-1, TNF- $\alpha$ and T-T (CPD)) of UVR-induced skin damage in a concentration-dependent manner. We also investigated the ability of other flavonols to protect skin against T-T (CPD) formation. We previously established that the general pattern of flavonol photostability follows the trend galangin $>$ kaempferol $>$ quercetin $>$ myricetin (54), as a result myricetin was not used in our EpiDerm ${ }^{\mathrm{TM}}$ studies. While we observed different markers of biological damage than previously reported, our results agree with studies on topical quercetin formulations which suggest the importance of quercetin stability in the prevention of UVRinduced skin damage $(67 ; 55)$. Our results suggest that flavonols may protect skin from UVR-induced damage, and that the more stable flavonols kaempferol and galangin may be the most promising topical skin photoprotectants.

\section{ACKNOWLEDGMENTS}

This work has been suported by the Natural Sciences and Engineering Research Council and the College of Pharmacy and Nutrition Research Trust. B.M.F. is a recipient of an $\mathrm{Rx} \& \mathrm{D}$ award and S.M. is a recipient of a University of Saskatchewan GTA. E.S.K. is a member of the Drug Discovery and Development Research Group. We wish to thank J Alcorn and $\mathrm{R}$ Singh for guidance on method validation, $\mathrm{D}$ Michel and $\mathrm{J}$ Buse for technical assistance and $\mathrm{J}$ Headley and $\mathrm{K}$ Peru at Environment Canada for help with the initial APCI studies.

\section{REFERENCES}

1. Godar DE. UV doses worldwide. Photochem Photobiol 2005 Jul;81(4):736-49.

2. Goltzman D. Vitamin D action : Lessons learned from genetic mouse models. Ann N Y Acad Sci 2010 Mar;1192(1):145-52.

3. Dixon KM, Sequeira VB, Camp AJ, Mason RS. Vitamin D-fence. Photochem Photobiol Sci 2010 Apr;9(4):564-70.

4. Taira J, Mimura K, Yoneya T, Hagi A, Murakami A, Makino K. Hydroxyl radical formation by UVirradiated epidermal cells. J Biochem (Tokyo) 1992 Jun;111(6):693-5.

5. Nishi J, Ogura R, Sugiyama M, Hidaka T, Kohno M. Involvement of active oxygen in lipid peroxide radical reaction of epidermal homogenate following ultraviolet light exposure. J Invest Dermatol 1991 Jul;97(1):115-9.

6. Longstreth J, de Gruijl FR, Kripke ML, Abseck S, Arnold F, Slaper HI, et al. Health risks. J Photochem Photobiol B 1998 Oct;46(1-3):20-39.

7. Ullrich SE. The role of epidermal cytokines in the generation of cutaneous immune reactions and ultraviolet radiation-induced immune suppression. Photochem Photobiol 1995 Sep;62(3):389-401.

8. Setlow RB, Grist E, Thompson K, Woodhead AD. Wavelengths effective in induction of malignant melanoma. Proc Natl Acad Sci U S A 1993 Jul 15;90(14):6666-70.

9. Ramakrishnan N, Pradhan DS. Occurrence of pyrimidine-rich tracts in ascites tumor DNA and the 
formation of UV-induced thymine dimers. Photochem Photobiol 1979 Mar;29(3):539-42.

10. Kuluncsics Z, Perdiz D, Brulay E, Muel B, Sage E. Wavelength dependence of ultraviolet-induced DNA damage distribution: involvement of direct or indirect mechanisms and possible artefacts. J Photochem Photobiol B 1999 Mar;49(1):71-80.

11. Niggli HJ, Cerutti PA. Cyclobutane-type pyrimidine photodimer formation and excision in human skin fibroblasts after irradiation with 313-nm ultraviolet light. Biochemistry 1983 Mar 15;22(6):1390-5.

12. Courdavault S, Baudouin C, Sauvaigo S, Mouret S, Candeias S, Charveron $\mathrm{M}$, et al. Unrepaired cyclobutane pyrimidine dimers do not prevent proliferation of UV-B-irradiated cultured human fibroblasts. Photochem Photobiol 2004 Feb;79(2):145-51.

13. Kielbassa C, Roza L, Epe B. Wavelength dependence of oxidative DNA damage induced by UV and visible light. Carcinogenesis 1997 Apr;18(4):811-6.

14. Ravanat JL, Douki T, Cadet J. Direct and indirect effects of UV radiation on DNA and its components. J Photochem Photobiol B 2001 Oct;63(1-3):88-102.

15. Einspahr JG, Stratton SP, Bowden GT, Alberts DS. Chemoprevention of human skin cancer. Crit Rev Oncol Hematol 2002 Mar;41(3):269-85.

16. Yarosh D, Dong K, Smiles K. UV-induced degradation of collagen $\mathrm{I}$ is mediated by soluble factors released from keratinocytes. Photochem Photobiol 2008 Jan;84(1):67-8.

17. Yarosh DB, Boumakis S, Brown AB, Canning MT, Galvin JW, Both DM, et al. Measurement of UVBInduced DNA damage and its consequences in models of immunosuppression. Methods 2002;28:55-62.

18. Kuchel JM, Barnetson RS, Halliday GM. Cyclobutane pyrimidine dimer formation is a molecular trigger for solar-simulated ultraviolet radiation-induced suppression of memory immunity in humans. Photochem Photobiol Sci 2005 Aug;4(8):577-82.

19. McLoone P, Woods GM, Norval M. Decrease in langerhans cells and increase in lymph node dendritic cells following chronic exposure of mice to suberythemal doses of solar simulated radiation. Photochem Photobiol 2005 Sep;81(5):1168-73.

20. Schade N, Esser C, Krutmann J. Ultraviolet B radiation-induced immunosuppression: molecular mechanisms and cellular alterations. Photochem Photobiol Sci 2005 Sep;4(9):699-708.

21. Rivas JM, Ullrich SE. Systemic suppression of delayed-type hypersensitivity by supernatants from UV-irradiated keratinocytes. An essential role for keratinocyte-derived IL-10. J Immunol 1992 Dec 15;149(12):3865-71.
22. Rivas JM, Ullrich SE. The role of IL-4, IL-10, and TNF-alpha in the immune suppression induced by ultraviolet radiation. J Leukoc Biol 1994 Dec;56(6):769-75.

23. Nishimura N, Tohyama C, Satoh M, Nishimura H, Reeve VE. Defective immune response and severe skin damage following UVB irradiation in interleukin-6-deficient mice. Immunology 1999 May;97(1):77-83.

24. Scharffetter-Kochanek K, Wlaschek M, Brenneisen P, Schauen M, Blaudschun R, Wenk J. UV-induced reactive oxygen species in photocarcinogenesis and photoaging. Biol Chem 1997 Nov;378(11):1247-57.

25. Wlaschek M, Bolsen K, Herrmann G, Schwarz A, Wilmroth F, Heinrich PC, et al. UVA-induced autocrine stimulation of fibroblast-derivedcollagenase by IL-6: a possible mechanism in dermal photodamage? J Invest Dermatol 1993 Aug;101(2):164-8.

26. Berneburg M, Plettenberg H, Krutmann J. Photoaging of human skin. Photodermatol Photoimmunol Photomed 2000 Dec;16(6):239-44.

27. Sander CS, Chang H, Salzmann S, Muller CS, Ekanayake-Mudiyanselage $\mathrm{S}$, Elsner $\mathrm{P}$, et al. Photoaging is associated with protein oxidation in human skin in vivo. J Invest Dermatol 2002 Apr;118(4):618-25.

28. Shin $\mathrm{MH}$, Rhie GE, Kim YK, Park $\mathrm{CH}$, Cho KH, $\mathrm{Kim} \mathrm{KH}$, et al. $\mathrm{H} 2 \mathrm{O} 2$ accumulation by catalase reduction changes MAP kinase signaling in aged human skin in vivo. J Invest Dermatol 2005 Aug;125(2):221-9.

29. Fisher GJ, Datta SC, Talwar HS, Wang ZQ, Varani J, Kang S, et al. Molecular basis of sun-induced premature skin ageing and retinoid antagonism. Nature 1996 Jan 25;379(6563):335-9.

30. Kang S, Fisher GJ, Voorhees JJ. Photoaging and topical tretinoin: therapy, pathogenesis, and prevention. Arch Dermatol 1997 Oct;133(10):12804.

31. Fisher GJ, Wang ZQ, Datta SC, Varani J, Kang S, Voorhees JJ. Pathophysiology of premature skin aging induced by ultraviolet light. N Engl J Med 1997 Nov 13;337(20):1419-28.

32. Scharffetter K, Wlaschek M, Hogg A, Bolsen K, Schothorst A, Goerz G, et al. UVA irradiation induces collagenase in human dermal fibroblasts in vitro and in vivo. Arch Dermatol Res 1991;283(8):506-11.

33. Budai M, Reynaud-Angelin A, Szabo Z, Toth S, Ronto G, Sage E, et al. Effect of UVA radiation on membrane fluidity and radical decay in human fibroblasts as detected by spin labeled stearic acids. J Photochem Photobiol B 2004 Dec 2;77(1-3):27-38.

34. Krol ES, Kramer-Stickland KA, Liebler DC. Photoprotective actions of topically applied vitamin E. Drug Metab Rev 2000 Aug;32(3-4):413-20. 
35. Wei H, Saladi R, Lu Y, Wang Y, Palep SR, Moore $\mathrm{J}$, et al. Isoflavone genistein: photoprotection and clinical implications in dermatology. J Nutr 2003 Nov;133(11 Suppl 1):3811S-9S.

36. Birt DF, Mitchell D, Gold B, Pour P, Pinch HC. Inhibition of ultraviolet light induced skin carcinogenesis in SKH-1 mice by apigenin, a plant flavonoid. Anticancer Res 1997 Jan;17(1A):85-91.

37. Scott AI. Interpretation of the Ultraviolet Spectra of Natural Products. New York: The MacMillan Company; 1964.

38. Wilson KE, Wilson MI, Greenberg BM. Identification of the flavonoid glycosides that accumulate in Brassica napus L. cv. Topas specifically in response to ultraviolet $\mathrm{B}$ radiation. Photochem Photobiol 1998 May;67(5):547-53.

39. Ryan KG, Markham KR, Bloor SJ, Bradley JM, Mitchell KA, Jordan BR. UVB radiation induced increase in quercetin: Kaempferol ratio in wild-type and transgenic lines of Petunia. Photochem Photobiol 1998 Sep;68(3):323-30.

40. Solovchenko A, Schmitz-Eiberger M. Significance of skin flavonoids for UV-B-protection in apple fruits. J Exp Bot 2003 Aug;54(389):1977-84.

41. Steerenberg PA, Garssen J, Dortant P, van d, V, Geerse L, Verlaan AP, et al. Quercetin prevents UVinduced local immunosuppression, but does not affect UV-induced tumor growth in SKH-1 hairless mice. Photochem Photobiol 1997 Apr;65(4):736-44.

42. Steerenberg PA, Garssen J, Dortant PM, van d, V, Geerse E, Verlaan AP, et al. The effect of oral quercetin on UVB-induced tumor growth and local immunosuppression in SKH-1. Cancer Lett 1997 Mar 19;114(1-2):187-9.

43. Vicentini FT, Fonseca YM, Pitol DL, Iyomasa MM, Bentley MV, Fonseca MJ. Evaluation of protective effect of a water-in-oil microemulsion incorporating quercetin against UVB-induced damage in hairless mice skin. J Pharm Pharm Sci 2010;13(2):274-85.

44. Lim H, Kim HP. Inhibition of mammalian collagenase, matrix metalloproteinase-1, by naturally-occurring flavonoids. Planta Med 2007 Oct;73(12):1267-74.

45. Vicentini FT, He T, Shao Y, Fonseca MJ, Verri WA, Jr., Fisher GJ, et al. Quercetin inhibits UV irradiation-induced inflammatory cytokine production in primary human keratinocytes by suppressing NF-kappaB pathway. J Dermatol Sci 2011 Mar;61(3):162-8.

46. Scalia S, Mezzena M. Photostabilization effect of quercetin on the UV filter combination, butyl methoxydibenzoylmethane-octyl

methoxycinnamate. Photochem Photobiol 2010 Mar;86(2):273-8.

47. Nakajima A, Tahara M, Yoshimura Y, Nakazawa H. Study of compounds suppressing free radical generation from UV-exposed ketoprofen. Chem Pharm Bull (Tokyo) 2007 Oct;55(10):1431-8.

48. Olson ER, Melton T, Dong Z, Bowden GT. Stabilization of quercetin paradoxically reduces its proapoptotic effect on UVB-irradiated human keratinocytes. Cancer Prev Res (Phila Pa) 2008 Oct;1(5):362-8.

49. Lee KM, Lee KW, Jung SK, Lee EJ, Heo YS, Bode AM, et al. Kaempferol inhibits UVB-induced COX2 expression by suppressing Src kinase activity. Biochem Pharmacol 2010 Dec 15;80(12):2042-9.

50. Jung SK, Lee KW, Byun S, Kang NJ, Lim SH, Heo YS, et al. Myricetin suppresses UVB-induced skin cancer by targeting Fyn. Cancer Res 2008 Jul 15;68(14):6021-9.

51. Kim W, Yang HJ, Youn H, Yun YJ, Seong KM, Youn B. Myricetin inhibits Akt survival signaling and induces Bad-mediated apoptosis in a low dose ultraviolet (UV)-B-irradiated HaCaT human immortalized keratinocytes. J Radiat Res (Tokyo) 2010;51(3):285-96.

52. Jung SK, Lee KW, Kim HY, Oh MH, Byun S, Lim $\mathrm{SH}$, et al. Myricetin suppresses UVB-induced wrinkle formation and MMP-9 expression by inhibiting Raf. Biochem Pharmacol 2010 May 15;79(10):1455-61.

53. Jung SK, Lee KW, Byun S, Lee EJ, Kim JE, Bode $\mathrm{AM}$, et al. Myricetin inhibits UVB-induced angiogenesis by regulating PI-3 kinase in vivo. Carcinogenesis 2010 May;31(5):911-7.

54. Fahlman BM, Krol ES. Inhibition of UVA and UVB radiation-induced lipid oxidation by quercetin. $\mathrm{J}$ Agric Food Chem 2009 Jun 24;57(12):5301-5.

55. Maini S, Hodgson HL, Krol ES. The UVA and aqueous stability of flavonoids is dependent on Bring substitution. J Agric Food Chem 2012 Jul 18;60(28):6966-76.

56. Ramsey RS, Ho C. Determination of pyrimidine dimers in DNA by high-performance liquid chromatography/gas chromatography and electron capture detection. Anal Biochem 1989 Nov 1;182(2):424-31.

57. McVean M, Liebler DC. Inhibition of UVB induced DNA photodamage in mouse epidermis by topically applied alpha-tocopherol. Carcinogenesis 1997 Aug;18(8):1617-22.

58. Fahlman BM, Krol ES. UVA and UVB radiationinduced oxidation products of quercetin. $\mathrm{J}$ Photochem Photobiol B 2009 Dec 2;97(3):123-31.

59. Lee KM, Lee KW, Jung SK, Lee EJ, Heo YS, Bode AM, et al. Kaempferol inhibits UVB-induced COX-2 expression by suppressing Src kinase activity. Biochem Pharmacol 2010 Dec 15;80(12):2042-9.

60. Jung SK, Lee KW, Byun S, Kang NJ, Lim SH, Heo $\mathrm{YS}$, et al. Myricetin suppresses UVB-induced skin 
cancer by targeting Fyn. Cancer Res 2008 Jul 15;68(14):6021-9.

61. Kim W, Yang HJ, Youn H, Yun YJ, Seong KM, Youn B. Myricetin inhibits Akt survival signaling and induces Bad-mediated apoptosis in a low dose ultraviolet (UV)-B-irradiated HaCaT human immortalized keratinocytes. J Radiat Res (Tokyo) 2010;51(3):285-96.

62. Vicentini FT, He T, Shao Y, Fonseca MJ, Verri WA, Jr., Fisher GJ, et al. Quercetin inhibits UV irradiation-induced inflammatory cytokine production in primary human keratinocytes by suppressing NF-kappaB pathway. J Dermatol Sci 2011 Jan 13.

63. Fagot D, Asselineau D, Bernerd F. Direct role of human dermal fibroblasts and indirect participation of epidermal keratinocytes in MMP-1 production after UV-B irradiation. Arch Dermatol Res 2002 Jan;293(11):576-83.
64. Scharffetter-Kochanek K, Wlaschek M, Briviba K, Sies H. Singlet oxygen induces collagenase expression in human skin fibroblasts. FEBS Lett 1993 Oct 4;331(3):304-6.

65. Herrmann G, Wlaschek M, Bolsen K, Prenzel K, Goerz G, Scharffetter-Kochanek K. Photosensitization of uroporphyrin augments the ultraviolet A-induced synthesis of matrix metalloproteinases in human dermal fibroblasts. J Invest Dermatol 1996 Sep;107(3):398-403.

66. Zhou A, Sadik OA. Comparative analysis of quercetin oxidation by electrochemical, enzymatic, autoxidation, and free radical generation techniques: a mechanistic study. J Agric Food Chem 2008 Dec 24;56(24):12081-91.

67. Wlaschek M, Briviba K, Stricklin GP, Sies H, Scharffetter-Kochanek K. Singlet oxygen may mediate the ultraviolet A-induced synthesis of interstitial collagenase. J Invest Dermatol 1995 Feb;104(2):194-8. 


\section{SUPPLEMENTARY MATERIAL}

Flavonols Protect Against UV Radiation-Induced Thymine Dimer Formation in an Artificial Skin Mimic.

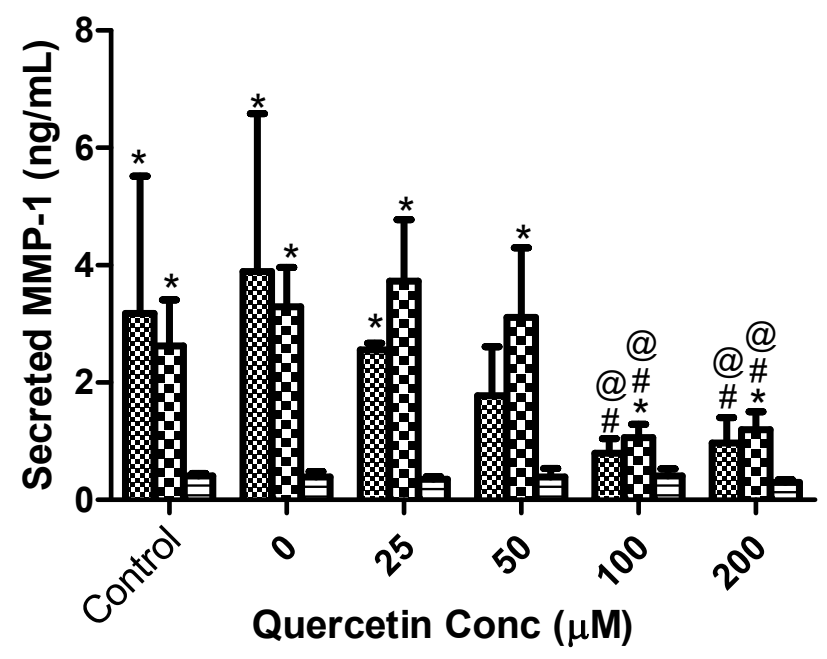

Figure 1S. Quercetin prevention of MMP-1 production by HaCaT cell cultures exposed to either $100 \mathrm{~kJ} / \mathrm{m}^{2} \mathrm{UVA}, 900 \mathrm{~J} / \mathrm{m}^{2}$ UVB (in open culture dishes, UVC removed by filtration) or no UVR (dark) by ELISA. Cell cultures were treated with quercetin in DMSO ( $<2 \%$ by volume) added to media 24 hours prior to exposure. For UVR exposure, media was replaced with phosphate buffered saline and then following treatment saline was replaced with DMEM and cells were returned to the incubator. Media was collected for pro-MMP-1 analysis 24 hours later and stored at $-80^{\circ} \mathrm{C}$ until analysis. $m=\mathrm{UVA}$, $\mathbf{\infty}=$ UVB Treatment, $\boldsymbol{\nabla}=$ Dark Control. $*=$ significantly different from dark control $(\mathrm{P}<0.05)$, \# = significantly different from control $(\mathrm{P}<0.05)$, @ = significant different from $0 \mu \mathrm{M}$ (vehicle control) $(\mathrm{P}<0.05)$.

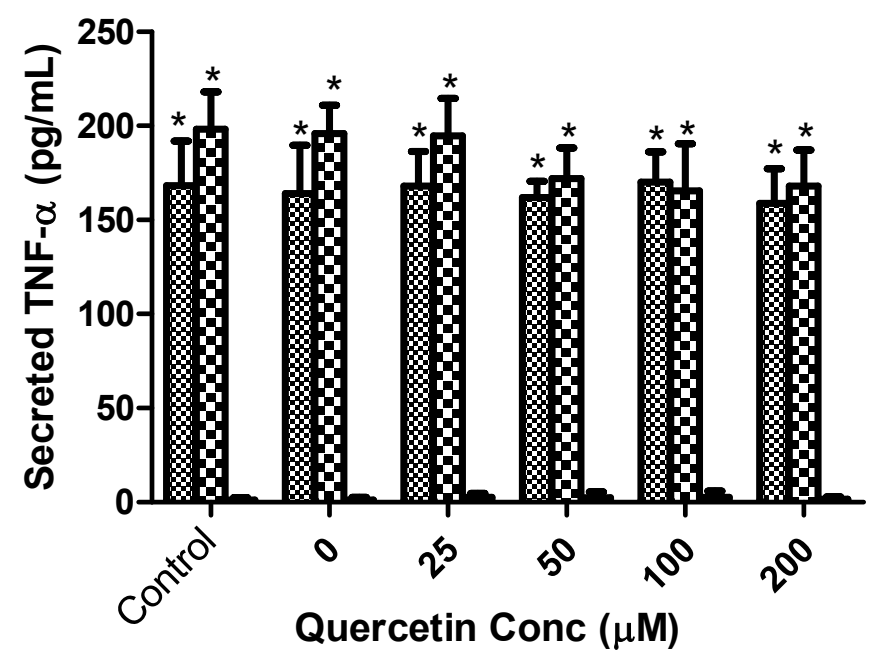

Figure 2S. Quercetin prevention of TNF- $\alpha$ production by $\mathrm{HaCaT}$ cell cultures exposed to either $100 \mathrm{~kJ} / \mathrm{m}^{2} \mathrm{UVA}, 900 \mathrm{~J} / \mathrm{m}^{2}$ UVB (in open culture dishes, UVC removed by filtration) or no UVR (dark) by ELISA. Cell cultures were treated with quercetin in DMSO $(<2 \%$ by volume) added to media 24 hours prior to exposure. For UVR exposure, media was replaced with phosphate buffered saline and then following treatment saline was replaced with DMEM and cells were returned to the incubator. Media was collected for TNF- $\alpha$ analysis 24 hours later and stored at $-80^{\circ} \mathrm{C}$ until analysis. $\mathbf{m}=\mathrm{UVA}$, $\mathbf{\boldsymbol { ⿴ }}=$ UVB Treatment, $\boldsymbol{\nabla}=$ Dark Control. $*$ = significantly different from dark control $(\mathrm{P}<0.05)$. 